\title{
Comparison of cloud statistics from spaceborne lidar systems
}

\author{
S. Berthier ${ }^{1,2, *}$, P. Chazette ${ }^{2}$, J. Pelon ${ }^{1}$, and B. Baum ${ }^{3}$ \\ ${ }^{1}$ Service d'Aéronomie du CNRS, Institut Pierre-Simon-Laplace, Université Pierre-et-Marie-Curie, 4, Place Jussieu-75252 \\ Paris Cedex 05, France \\ ${ }^{2}$ Laboratoire des Sciences du Climat et de l'Environnement, Laboratoire mixte CEA-CNRS, F-91191 Gif-sur-Yvette, France \\ ${ }^{3}$ Space Science and Engineering Center, 122 W Dayton Street, Madison, WI 53706, USA \\ *now at: Space Science and Engineering Center, 1225 W. Dayton Street, Madison, WI 53706, USA
}

Received: 19 November 2007 - Published in Atmos. Chem. Phys. Discuss.: 12 March 2008

Revised: 15 October 2008 - Accepted: 15 October 2008 - Published: 3 December 2008

\begin{abstract}
The distribution of clouds in a vertical column is assessed on the global scale through analysis of lidar measurements obtained from three spaceborne lidar systems: LITE (Lidar In-space Technology Experiment, NASA), GLAS (Geoscience Laser Altimeter System, NASA), and CALIOP (Cloud-Aerosol LIdar with Orthogonal Polarization). Cloud top height (CTH) is obtained from the LITE profiles based on a simple algorithm that accounts for multilayer cloud structures. The resulting CTH results are compared to those obtained by the operational algorithms of the GLAS and CALIOP instruments. Based on our method, spaceborne lidar data are analyzed to establish statistics on the cloud top height. The resulting columnar results are used to investigate the inter-annual variability in the lidar cloud top heights. Statistical analyses are performed for a range of CTH (high, middle, low) and latitudes (polar, middle latitude and tropical). Probability density functions of CTH are developed. Comparisons of CTH developed from LITE, for 2 weeks of data in 1994, with ISCCP (International Satellite Cloud Climatology Project) cloud products show that the cloud fraction observed from spaceborne lidar is much higher than that from ISCCP. Another key result is that ISCCP products tend to underestimate the $\mathrm{CTH}$ of optically thin cirrus clouds. Significant differences are observed between LITE-derived cirrus CTH and both GLAS and CALIOP-derived cirrus CTH. Such a difference is due primarily to the lidar signal-to-noise ratio that is approximately a factor of 3 larger for the LITE system than for the other lidars. A statistical analysis for a full year of data highlights the influence of both the InterTropical Convergence Zone and polar stratospheric clouds.
\end{abstract}

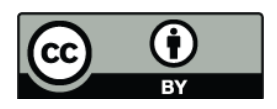

Correspondence to: S. Berthier (sebastien.berthier@ssec.wisc.edu)

\section{Introduction}

One of the most challenging objectives of current climate research programs is in understanding the impact of clouds on the global energy budget and hydrological balance. Indeed, clouds have a significant influence on the Earth's radiative balance and induce various climatic feedbacks that are not well known (e.g. Stephens, 2005; Forster et al., 2007). One important issue is the cloud spatial and vertical distribution (e.g. Rossow and Schiffer, 1991). The vertical distribution of the cloud layers in an atmospheric column can lead to very different assumptions of cloud overlap in numerical models. Clouds influence the heating rates and the radiative energy budget. Feedbacks due to cirrus clouds are an important issue in climate modeling as they have a significant radiative impact which largely depends on their characteristics. Such feedbacks become more complex if lower-level clouds are present. To properly model overlapping cloud layers, it is necessary to know the thermodynamic phase of each cloud layer in addition to the other properties such as height, optical thickness, and effective particle size. Multilayered, overlapping clouds are presently poorly modeled because their life cycle implies dynamical processes at scales much smaller than those used in general circulation model (GCM) calculations, and also because of their complex microphysics (Flatau et al., 1989). A better knowledge of the horizontal and vertical distribution of all cloud layers is required to improve cloud parameterization in existing climatic models and better assess their feedbacks. Numerous previous studies have been performed using spaceborne passive instruments to infer the vertical distribution of clouds, e.g. combination of ISCCP and SSM/I (Yeh et Liou, 1983), NIMBUS 7 (Stowe, 1984), TOVS (Susskind et al., 1987), 3DNEPH and RDNEPH (Hughes and Henderson-Sellers, 1985), ISCCP (Rossow et al., 1985), combination of AVHRR and HIRS/2 (Baum et al., 1995), AVHRR (Pavolonis and Heidinger, 2004; Heidinger and Pavolonis, 2005), MODIS

Published by Copernicus Publications on behalf of the European Geosciences Union. 


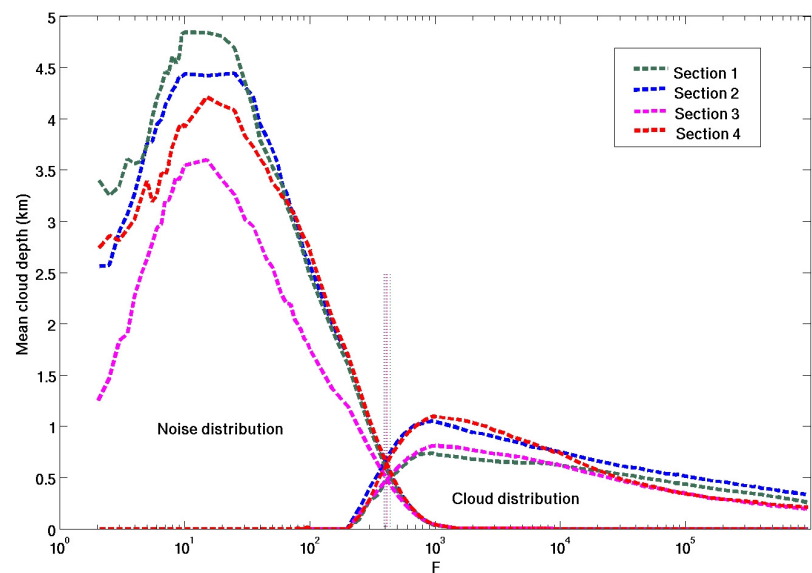

Fig. 1. Distributions of both the mean cloud geometric thickness and the signal noise against the value of the threshold $F$ for GLAS measurements. The Glas/ICESat datas used for this study are from 13 October 2003. Data are collected betwen 16:39 and 16:59 (GMT) for Sect. 1, 16:59 and 17:19 (GMT) for Sect. 2, 17:19 and 17:39 (GMT) for Sect. 3, and 18:20 and 18:40 (GMT) for Sect. 4. Here, $F$ has been assessed to be equal to $395,441,413$ and 411 , for respectively Sects. 1, 2, 3 and 4.

(Baum et al., 2003; Nasiri and Baum, 2004; Chang and Li, 2005), SAGE-II (Kent et al., 1993), and HIRS/2 (Jin and Rossow, 1997; Wylie et al., 2005). Even with techniques now available that show some facility in detecting the occurrence of multiple, but overlapping, cloud layers in passive radiometric data, it is still problematic to infer the properties of each cloud layer. Lidar offers the opportunity to better determine the presence of optically thin ice clouds and to detect lower-level stratiform systems (e.g. Winker et al., 1998). Active measurements may also be used to mitigate biases in cloud top heights that arise in complex situations, such as in the polar regions. New spaceborne backscatter lidar missions (ESA: Ingnam et al., 2008 and http://www.esa.int/ export/esaLP/index.html, NASA: http://www.veg3dbiomass. org/VolzVeg3Dworkshop.pdf) are currently underway or in preparation to give further insight on the spatial and vertical distribution of both clouds and aerosols in the troposphere, on a continuous observational basis as required by the models. However, compared to ground-based systems, spaceborne lidar systems provide an atmospheric backscattered signal with a relatively weak signal to noise ratio (SNR), thus requiring significant signal processing (e.g. Chazette et al., 2001).

In this study, we develop and apply a methodology to derive the probability density function (PDF) of cloud layer structures from lidar profiles obtained during the LITE (Lidar In-space Technology Experiment, (Winker, 1996) mission in September 1994. This pioneering mission provides an opportunity to estimate the cloud spatial distribution with a high spatial resolution under a given satellite footprint. The PDF retrieved from LITE data are compared with those calculated from the new spaceborne lidar missions, such as GLAS (Geoscience Laser Altimeter System, Palm et al., 1998) and CALIOP (Cloud-Aerosol Lidar with Orthogonal Polarization, (Winker et al., 2002). The GLAS and CALIOP data are processed two ways: (1) with the methodology developed for the LITE profiles and (2) the methodology used for the operational products. For the LITE time period in 1994, we perform comparisons to the ISCCP cloud products (Rossow and Schiffer, 1991). A full year of products generated from CALIOP is used to analyze the impact of the ITCZ latitudinal position and the occurrence of polar stratospheric clouds (PSC) on the intra- and inter-annual lidar signal variability.

\section{Method and spaceborne observations}

Different approaches have been developed to retrieve the cloud top height (CTH) from spaceborne lidar systems. Such approaches have been used for the operational algorithms for GLAS (Palm and Spinhirne, 1998) and CALIPSO (CloudAerosol Lidar Pathfinder Satellite Observation) (Vaughan et al., 2004) missions. Based on spaceborne lidar modeling performed by Chazette et al. (2001), we suggest an alternative methodology to retrieve the CTH for both semi-transparent and dense clouds and apply this methodology to the LITE data.

\subsection{Algorithm to retrieve the cloud top heights}

We adapt the method developed by Chazette et al. (2001) to infer the CTHs of scattering layers in the atmosphere from simulated spaceborne lidar signals with low signal to noise ratios $(\sim 3)$ to actual spaceborne lidar measurements. The method will be called the "Local Method" hereafter.

To determine the existence of a peak (i.e., a cloud) in a lidar calibrated and attenuated backscatter signal $S$ at any altitude level $i$ requires an ability to discriminate between an actual signal and signal noise. Here, the discrimination is performed by determining a threshold value $F$. The value of $F$ is proportional on the signal noise, which is used to define the variance $\mathrm{Var}$ as follows:

$$
\operatorname{Var}(k)=\frac{1}{2 n+1} \sum_{i=k-n}^{k+n}\left[\frac{S[i]-\bar{S}}{\sigma_{N}}\right]^{2}>F,
$$

where $(2 n+1)$ is the number of points of the filtering window. A constant size is assumed for the windows, with $\mathrm{n}$ equal to 3 , corresponding to a window size equivalent to 7 pixels. $\bar{S}$ and $\sigma_{\mathrm{N}}$ are respectively the mean value of the detected signal and the noise standard deviation in an altitude range where only noise is expected to be present (i.e., between 19 and $20 \mathrm{~km}$ height).

Figure 1 provides an example of the determination of $F$ for GLAS. This figure gives the mean cloud depth as a function of $F$. The method has been optimized based on the depth 
of the scattering layers so that the only cloud structures considered have a geometrical depth larger than $100 \mathrm{~m}$. This approach attempts to minimize the number of false alarms.

For a value of $F$ in the interval of 1 to 10, most of the values of Var are greater than $F$. This means that for an individual altitude level, the noise dominates the measurement and it is not possible to discern the presence of a cloud. If this situation occurs at every altitude, the lidar shot is not used in our analysis. As values of $F$ increase between 10 to 1000 , fewer lidar signals are misclassified as cloudy structures. The misclassifications between noise and an actual cloud structure are further reduced in the case of the LITE data by using a median filter. For values of $F>1000$, the lidar signal from a cloudy structure is more certain to not be caused by signal noise.

Two distributions are thus retrieved; the first is associated with the noise and the second is associated with the scattering layers themselves. A value for $F$ is inferred from the intersection of these two distributions to minimize the error probability that is a function of the no detection and false alarm probabilities (Chazette et al., 2001).

From all the structures identified after the first step of the algorithm, we further discriminate between clouds and aerosols. However, this operation can be quite difficult for lidar data, primarily for the case of dust aerosol that is denoted by a low Angström exponent (Grant et al., 1997). Different classification approaches have been suggested for GLAS (Palm et al., 2002) and CALIOP (Vaughan et al., 2004; Liu et al., 2004) lidar profiles. We use the GLAS prototype algorithms to separate clouds and aerosols in the LITE data processing between the ground level and the altitude of $8 \mathrm{~km}$. The lidar signal is explained in term of the attenuated volume backscatter coefficient $\beta^{\prime}(r)$ (Platt et al., 1998), i.e., to the calibrated, range-corrected lidar signals within each layer. The discriminator used here is based on the threshold relation given by $P=\beta_{\max }^{\prime}\left|\Delta \beta^{\prime} / \Delta \mathrm{z}\right|_{\max }>X$. $\beta_{\max }$ is the maximum attenuated backscatter of the layer and $\left|\Delta \beta^{\prime} / \Delta z\right|_{\max }$ is the maximum vertical gradient magnitude within the layer. $X$ defines the thresholds previously defined. Layers with values of $P$ larger than $X$ are interpreted as cloud whereas the others are classified as aerosol. After a statistical study, we determined the value of $X$ to be $3.10^{10} \mathrm{~m}^{-3} \cdot \mathrm{sr}^{-2}$.

The altitude range of the resulting CTHs is classified following the ISCCP approach: low (L), middle (M) and high $(\mathrm{H})$ clouds corresponding to pressure levels of 1000 to $680 \mathrm{hPa}, 680$ to $440 \mathrm{hPa}$, and 440 to $50 \mathrm{hPa}$, respectively (Rossow and Schiffer, 1991).

\subsection{Spaceborne datasets}

The LITE data were recorded on board the Space Shuttle Discovery during the NASA space shuttle mission STS-64 in September 1994. Over 11-day period of the mission, the LITE instrument accumulated $53 \mathrm{~h}$ of data (i.e. 70 available orbits) with a pulse repetition rate of $10 \mathrm{~Hz}$, at $\sim 240 \mathrm{~km}$ height, within a few degrees of nadir at three wavelengths: 355,532 , and $1064 \mathrm{~nm}$. The vertical resolution is $15 \mathrm{~m}$ and the horizontal sampling is $700 \mathrm{~m}$ along the footprint. Only the data at $532 \mathrm{~nm}$ are used in this study because of its better signal to noise ratio, which is close to 9 in the planetary boundary layer (PBL). LITE database contains only level 1 (calibrated and geolocated lidar backscatter profiles) data that can be accessed at http://www-lite.larc.nasa.gov.

The GLAS instrument was on the satellite platform called ICESat (Ice, Cloud and land Elevation Satellite, http://icesat. gsfc.nasa.gov/. ICESat was launched on 13 January 2003, had an inclined orbit of about $94^{\circ}$, and an altitude of about $590 \mathrm{~km}$ at the equator. The vertical and the horizontal resolution of the collected data are respectively $76.8 \mathrm{~m}$ and $175 \mathrm{~m}$. Despite a pre-launch goal for the lidar of 3 years continuous operation, the GLAS Operation Center needed to reduce the energy and the time period of the lidar activities because of a technical malfunction of the lidar (Thome et al., 2004; Abshire, 2005). In this study, we use data from laser $2 \mathrm{~A}$ that was recorded before a temperature anomaly occurred, and for the same season as when LITE was in operation, i.e. between the 25 September 2003 and 3 October 2003. Raw data at $532 \mathrm{~nm}$ (named Level 1) and the Level-2 official GLAS cloud product are used in this study to assess the accuracy of our algorithm. The GLAS data are characterized by a lower SNR than that of LITE, close to 1.5 in the PBL, due to the higher altitude of the satellite and the lower energy emitted by the instrument. GLAS database includes level 1 and level 2 (derived products such as CTHs, optical depth,...) data (available at http://nsidc.org/data/icesat.data.html).

The CALIOP instrument is on the CALIPSO satellite platform. The CALIPSO satellite was inserted in the ATrain constellation (http://www-calipso.larc.nasa.gov/about/ atrain.php) behind Aqua on 28 April, 2006. This satellite, which resulted from a collaboration between NASA and CNES, began to collect data in June 2006. This database is the first to provide more than one year of spaceborne lidar observations of the atmosphere. Hence both cloud and aerosol seasonal variations may be studied with a high vertical resolution. The mean altitude of the satellite is $705 \mathrm{~km}$, resulting in vertical and horizontal resolutions of 30 and $330 \mathrm{~m}$, respectively. The inclination of the satellite is about $98.2^{\circ}$, and thus covers the polar regions. The technology of the GLAS and the CALIOP instrument are quasi-similar, but operational modes are different. The SNR values are similar to that of the GLAS instrument $(\sim 2.1)$. CALIOP level 1 and level 2 data can be accessed at http://eosweb.larc.nasa.gov/ PRODOCS/calipso/tablecalipso.html or at http://www.icare. univ-lille1.fr.

The ISCCP database (Schiffer and Rossow, 1983), collects analyzed infrared $(11 \mu \mathrm{m})$ and visible $(0.6 \mu \mathrm{m})$ radiances measured by the operational geostationary and polarorbiting weather satellites. The ISCCP products provide a detailed description of the horizontal variations of cloud top pressure and optical thickness. The horizontal resolution 

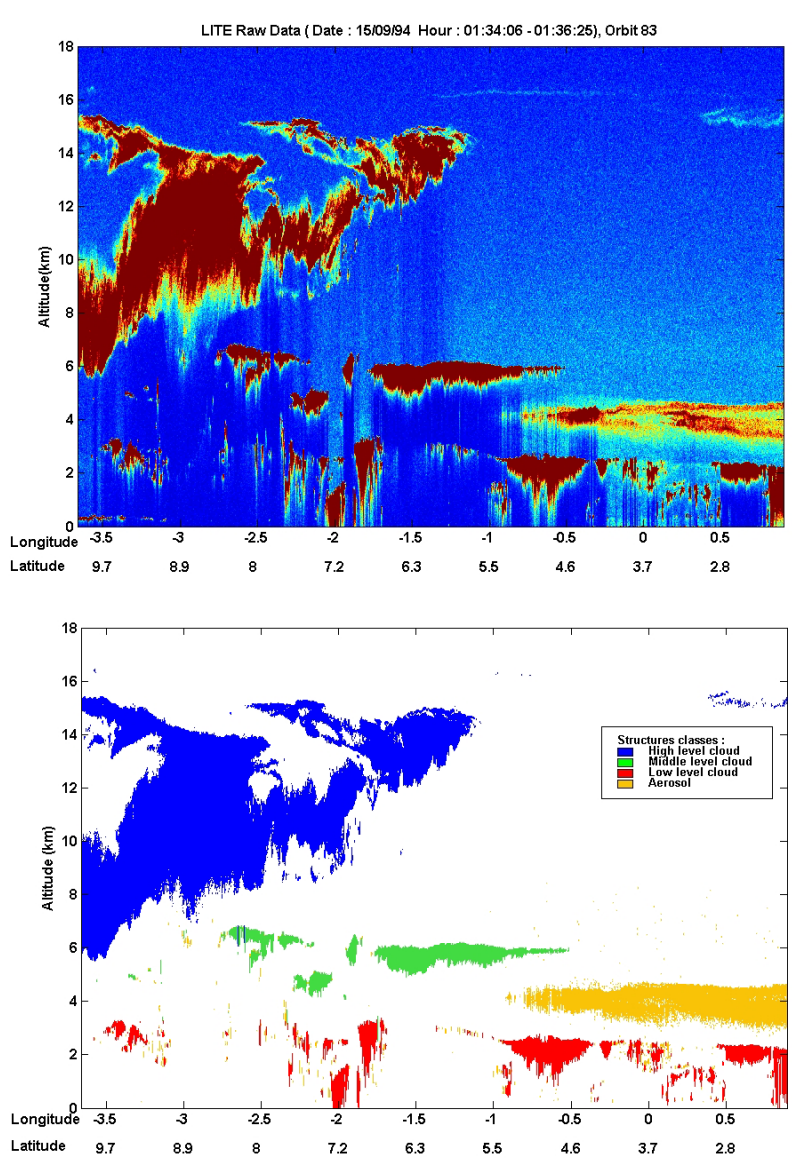

Fig. 2. Raw LITE data for 15 September 1994 (orbit 83) are given in the upper figure. The result of the classification of clouds and aerosol layers is given in the lower figure. The red, green and blue colors patches correspond to the clouds of Low, Middle and High altitude Level, respectively. The orange color corresponds to the dust aerosol layer.

of the ISCCP-DX data, used in this work, is $30 \times 30 \mathrm{~km}^{2}$ (http://climserv.lmd.polytechnique.fr). The ISCCP dataset is built from Meteosat (http://www.eumetsat.int), GOES (Geostationary Operational Environmental Satellites, http://www. goes.noaa.gov/) and TOVS (TIROS-N Operational Vertical Sounder, http://www.class.noaa.gov/) measurements.

\section{Classification of clouds and aerosols}

A case study illuminates the classification of clouds and aerosols in the lidar data. Figure 2 gives an example of the classification results for the LITE orbit 83 in 15 September 1994. The layers of clouds and aerosols are quite distinct. In particular, the layers of low, middle and high clouds are quite separate.

In the case of LITE data, there is no existing Level 2 cloud product so we will use the results derived from the Local Al-

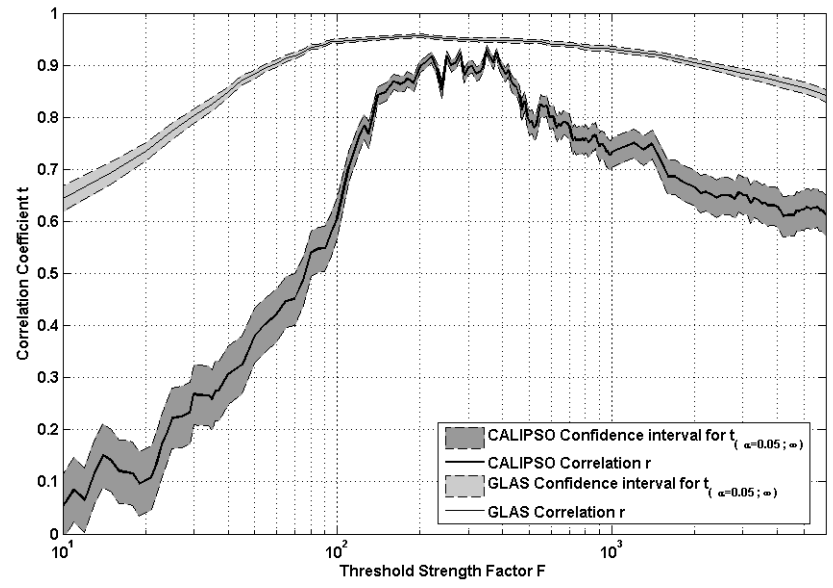

Fig. 3. Correlation between the Local Method and the operational algorithm of GLAS and CALIOP lidar against the value of $F$. Considering the GLAS data, the segment that are been considered are the same that ones used to construct the Fig. 1. For the CALIPSO data, the used data come from the day of the 26 June 2006, at 20:52 GMT.

gorithm presented in Sect. 2.1. To compare the cloud classifications performed from the previous algorithm and the operational algorithms of the GLAS and CALIPSO missions, it is necessary to evaluate the coherence between their respective results. For the CTH of only the uppermost structure on each lidar shot, we calculated the coefficients of correlation between each operational algorithm and the Local Method for cloudy scenes observed by GLAS and CALIOP. Figure 3 shows the results for GLAS and CALIOP according to the value of $F$. The maximum level of correlation is reached for a value of $F$ close to 400 for both GLAS and CALIOP. These values correspond to the thresholds that we will use in subsequent analyses. The correlation is high with values of 0.95 and 0.93 for GLAS and CALIPSO, respectively. The variations observed are related primarily to the non-detection of cloudy structures associated with low optical thickness (lower than 0.1 at the wavelength of $532 \mathrm{~nm}$ ) by both GLAS and CALIOP. Indeed, the detection of the semitransparent scattering structures is less sensitive with GLAS and CALIOP because the signal to noise ratio is weaker than that of LITE. The limits of cloud detection that result from different SNR values have implications for the statistics of global cloud cover presented later in this article.

\section{Lidar-derived cloud top height}

Now that some understanding has been gained of the coherence between the various algorithms for the identification of cloudy structures, the associated statistical distributions of the CTHs can be compared. 

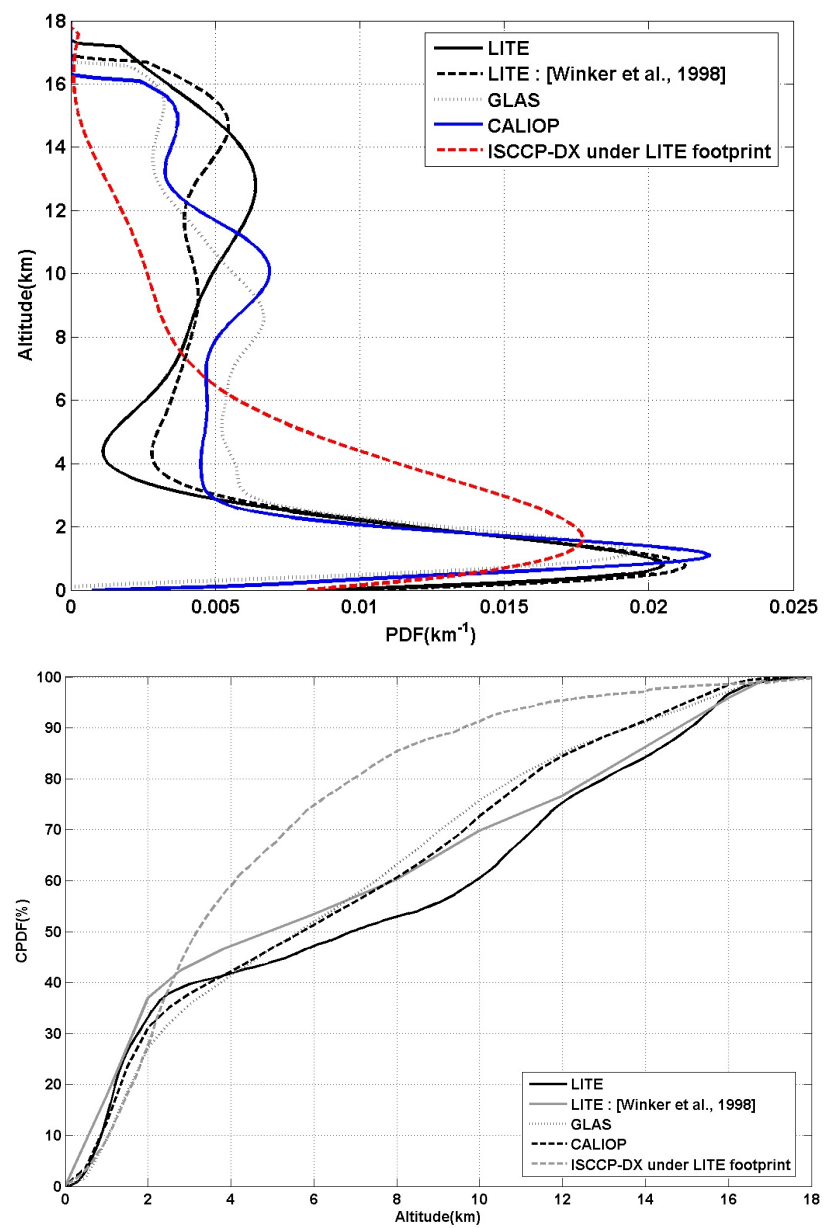

Fig. 4. Cloud top height probability density functions(Fig. 4a) and cumulative PDF (CPDF)(Fig. 4b) for the highest cloud structure established from: LITE (Local Method applied on September 1994), GLAS (Operational Algorithm, applied on last week of September and two first week of October 2003) and CALIOP (Operational Algorithm, applied on September 2006. The CPDF previously retrieved by Winker et al. (1998) with LITE data and the CDPF for ISCCP on the footprint of the LITE orbits on September 1994 are also given. Plots of the Fig. 4a are filtered to allow better comparisons.

\subsection{Cloud top cpdf}

Figure $4 \mathrm{a}$ and $4 \mathrm{~b}$ shows respectively the top of cloud PDF, and cumulative PDF (CPDF) as obtained from the datasets of LITE (Local Method), GLAS (Operational Algorithm) and CALIOP (Operational Algorithm). These CPDF indicate good agreement for low-level clouds up to an altitude of approximately $3 \mathrm{~km}$. There are very few differences between GLAS and CALIOP for all CTH, whereas the LITE CPDF shows a stronger sensitivity to high clouds. Since LITE has a higher value of the signal to noise ratio, it is better able to detect high altitude semitransparent cloud structures. Note that for the low level clouds $(\mathrm{CTH}<\sim 3 \mathrm{~km})$, the
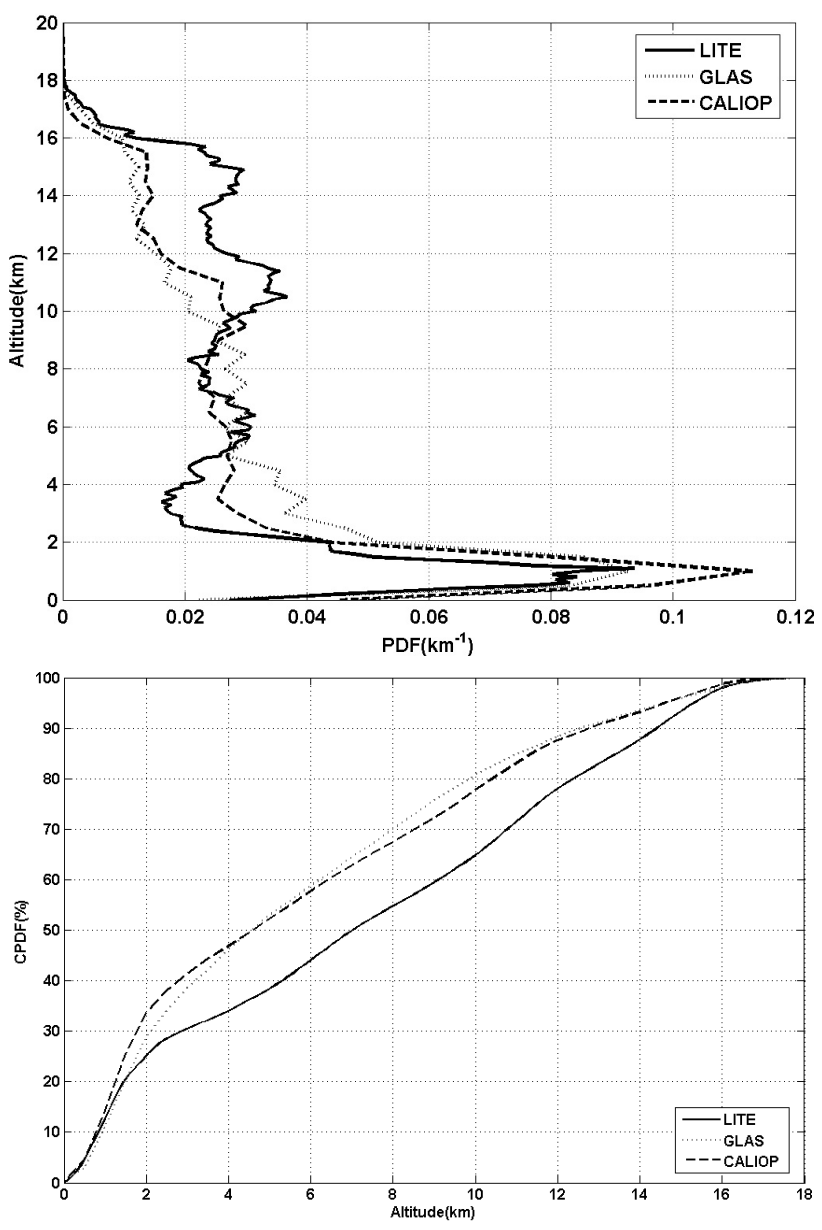

Fig. 5. Cloud top height probability density functions(Fig. 5a) and cumulative PDF (CPDF)(Fig. 5b) for all the cloud structure established from LITE, and CALIOP at the same date as for Figs. 4a and b.

results in Fig. 4b are in good agreement with surface observations (Warren et al., 1985) that provide an estimate of the percentage of low level clouds without any cloud above to be about $40 \%$. Winker et al. (1998) show about the same CPDF as that retrieved from the Local Method.

When the upper cloud structure is semitransparent, the lidars offer the possibility of identifying lower-level scattering layers. The efficiency of lower scattering layer detection is directly linked to the signal to noise ratio. Figure $5 \mathrm{a}(\mathrm{b})$ gives the PDF(CPDF) for all the cloud structures for each spaceborne lidar. They are similar for GLAS and CALIPSO with a slight increase of middle-altitude clouds. The difference is more important for LITE where more low level cloud structures are detected. In this last case, the CPDF reach about the same value $(\sim 45 \%)$ at an altitude of approximately $6 \mathrm{~km}$. 


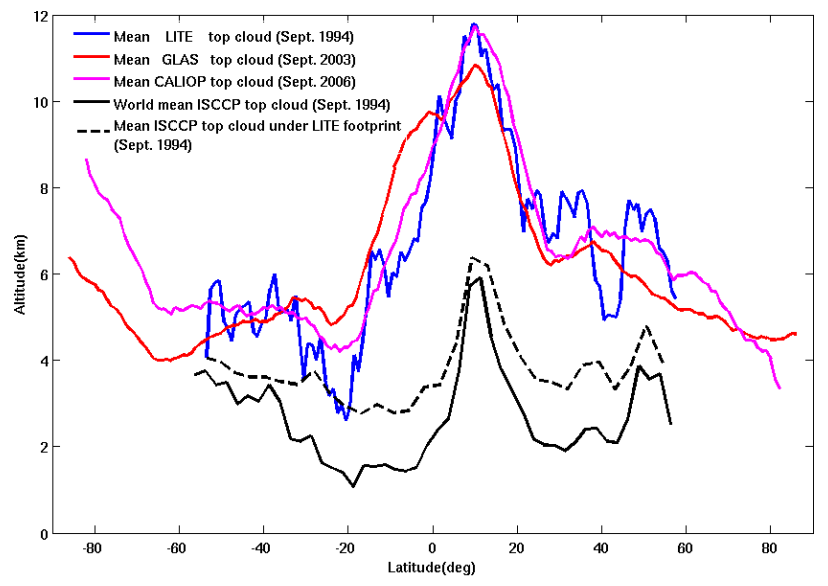

Fig. 6. Mean cloud top height against the altitude of the highest structure for LITE (Local Method applied on September 1994), GLAS (operational algorithm applied on the last week of September and the two first week of October 2003) and CALIOP (operational algorithm applied on September 2006). The mean cloud top height given for both the global coverage of ISCCP data and the ISCCP data under the LITE footprint on September 1994 is also given.

\subsection{Latitudinal cloud top height distributions}

\subsubsection{Mean cloud top height}

Figure 6 gives the mean $\mathrm{CTH}$ for the highest-level structure as a function of the latitude for LITE, GLAS and CALIOP. The acquisition periods are different. Ten days are considered for the LITE mission on September 1994. A full month (September 2006) of CALIOP is analyzed, and for GLAS the time period encompasses the last week of September and the two first weeks of October 2003. The reduced number of days for LITE mission may contribute to the greater variability of the data. No significant difference in the shape was observed on GLAS data when splitting the data into weekly sequences.

Between $60^{\circ} \mathrm{S}$ and $60^{\circ} \mathrm{N}$, there is good agreement between the observations of the various missions, which is fortunate considering difference in the acquisition periods and the potential for interannual variability to influence the results. The northern maximum near $10^{\circ} \mathrm{N}$ corresponds to the position of the ITCZ (Inter Tropical Convergence Zone) in September (Waliser et al., 1993). The ITCZ moves seasonally, following the solar heating and the warmest surface temperatures: it moves toward the Southern Hemisphere from September through February and reverses from March through August.

Mean CTHs are calculated for clouds ranging between $6 \mathrm{~km}$ and $11.5 \mathrm{~km}$ in the tropical latitudes. Minima are found near $20^{\circ} \mathrm{S}$ and near $30^{\circ} \mathrm{N}$, corresponding to the descending circulation of the Hadley cell. In the latitude range $\left[-60^{\circ}\right.$; $\left.-20^{\circ}\right]$ and $\left[30^{\circ} ; 60^{\circ}\right]$ corresponding to the midlatitudes, the mean CTH varies between 4.5 and $6.5 \mathrm{~km}$. Only the GLAS and CALIOP measurements provide data at latitudes higher than $60^{\circ}$ because the inclination of the LITE orbit is only $57^{\circ}$.

Between $60^{\circ} \mathrm{N}$ and $82^{\circ} \mathrm{N}$, the mean CTH tends to decrease linearly from 6 to $4 \mathrm{~km}$ (5 to $4.5 \mathrm{~km}$ ) height from CALIPSO (GLAS) measurements. There is no significant difference between the two spaceborne lidar observations. On the contrary, between $60^{\circ}$ and $82^{\circ} \mathrm{S}$, the mean CTH tends to increase from 4 to $6.3 \mathrm{~km}$ height for GLAS measurements, and from 5.1 to $8.6 \mathrm{~km}$ height for CALIPSO measurements. Such a difference may be due to the presence of polar stratospheric clouds (PSC). It is interesting to note that Höpfner et al. (2007) showed a stronger occurrence of PSC in $2006 \mathrm{com}-$ pared to 2003 using MIPAS/Envisat (Michelson Interferometer for Passive Atmospheric Sounding) instrument (Burkert et al., 1993).

Winker et al. (2007) demonstrated the capabilities of CALIOP measurements to provide high resolution vertical profiles to a latitude of $82^{\circ} \mathrm{S}$. Winker et al. (2007) showed that clouds observed over the East Antartic plateau in the middle of the Antartic Winter were relatively tenuous PSC extending up to $\sim 25 \mathrm{~km}$. Pitts et al. (2007) analysed such PSC structures from the CALIPSO database and document the occurrence of extensive PSC over large regions of Antartica throughout the 2006 Austral winter. They show that the 2006 season is very similar to the cold 1987 season, with a higher probability of occurrence under $16 \mathrm{~km}$ in September. Furthermore, in a personal communication, C. David, PI of the LOANA (Lidar Ozone and Aerosol for NDSC in Antarctica) ozone lidar, based at the French NDSC Station of Dumont d'Urville, confirms that there was a high occurrence of PSCs in 2006. The influence of PSC on the CTH will be discussed again in a later section.

\subsubsection{Distributions as functions of latitude and $\mathrm{CTH}$}

Figure 7 shows the two-dimensional histograms as a function of latitude and altitude of the CTH. The occurrences are given for the LITE, GLAS and CALIPSO missions, respectively. They show strong similarities but with a noisier pattern for the LITE-derived CTH. However, this variability may be caused by a sampling issue, with LITE providing a lower number of observations compared to GLAS and CALIOP measurements.

In the following discussion, low-level clouds are defined as having cloud-top pressures ranging from $1000-680 \mathrm{hPa}$; middle-level and high-level clouds ranging respectively from 440-680 hPa and 440-50 hPa.

For the three cases, a low cloud pattern is observed between 0 and $2 \mathrm{~km}$ with a maximum in the frequency of occurrence at a height close to $1.5 \mathrm{~km}$. A minimum in the frequency of low cloud occurrences is observed near the location of the ITCZ due to the presence of high optically dense clouds that mask the potential presence of low- and midlevel cloud structures. For all cases a strong occurrence of high 
clouds is clearly highlighted between 13 and $18 \mathrm{~km}$ height in the ITCZ region, i.e. between $\left[10^{\circ} \mathrm{S} ; 20^{\circ} \mathrm{N}\right]$, corresponding to regions of deep convection, and the occurrence of cumulonimbus and cirrus clouds. Generally, one finds higher occurrences of cloud near the tropopause, in particular for the northern middle latitudes and the polar latitudes $\left(>60^{\circ}\right)$. The altitude of the maximum cloud occurrence decreases with increasing latitude. The higher frequency of occurrence of high clouds is mainly due to the presence of optically thin cirrus clouds.

To summarize the previous results, lidar-derived cloud statistics based on only the uppermost cloud layer on each lidar shot from LITE, GLAS and CALIOP are given in Table 1. Cloud statistics are calculated for the latitude intervals defined by $\left[60^{\circ} \mathrm{S} ; 20^{\circ} \mathrm{S}\right],\left[20^{\circ} \mathrm{S} ; 30^{\circ} \mathrm{N}\right]$ and $\left[30^{\circ} \mathrm{N} ; 60^{\circ} \mathrm{N}\right]$. These intervals were chosen from the two-dimensional distributions of the CTH shown on Figs. 6 and 7.

The global cloud fractions are similar for the three datasets with values of $69.8 \%, 69.2 \%$ and $70.5 \%$ for LITE, GLAS and CALIOP measurements, respectively. This is somewhat surprising, as LITE should be able to detect more clouds due to its better SNR. A strong occurrence of high altitude clouds is highlighted $(52 \%, 46.5 \%$ and $45 \%$ for LITE, GLAS and CALIOP measurements, respectively) representing half of the detected cloud structures. LITE detects more high clouds than GLAS and CALIPSO, probably due to its better sensitivity (SNR). Detected low cloud fraction is comparable in the three datasets. However, middle-altitude clouds are more frequently detected by GLAS and CALIPSO than by LITE (9.8 and $4.9 \%$, respectively). Besides a difference in atmospheric cloud structure due to inter-annual variability, this may be also be attributed to some extent to the larger multiple scattering (MS) impact in LITE measurements. MS increases signal at altitudes below an upper cloud layer, and may prevent the detection of a second lower cloud layer with our algorithm. Lower level clouds tend to be composed of liquid water and are less perturbed by MS from upper cloud layers due to their larger backscatter coefficient.

There is less cloud fraction variability between the tropical and middle latitudes. However, we find that the latitude interval between $\left[60^{\circ} \mathrm{S} ; 20^{\circ} \mathrm{S}\right]$ has a higher proportion of low clouds that may exceed 50\% although it is lower in the case of GLAS ( 33\%).

The relatively high frequency of occurrence of high cloud structures at latitudes greater than $60^{\circ}$ for the GLAS and CALIOP instrument may be related to the tightening of the orbit footprints for these latitudes. Some caution must be exercised with the interpretation of high clouds in polar latitudes. There may be over-representation of the high cloud structures of greater horizontal expansion.
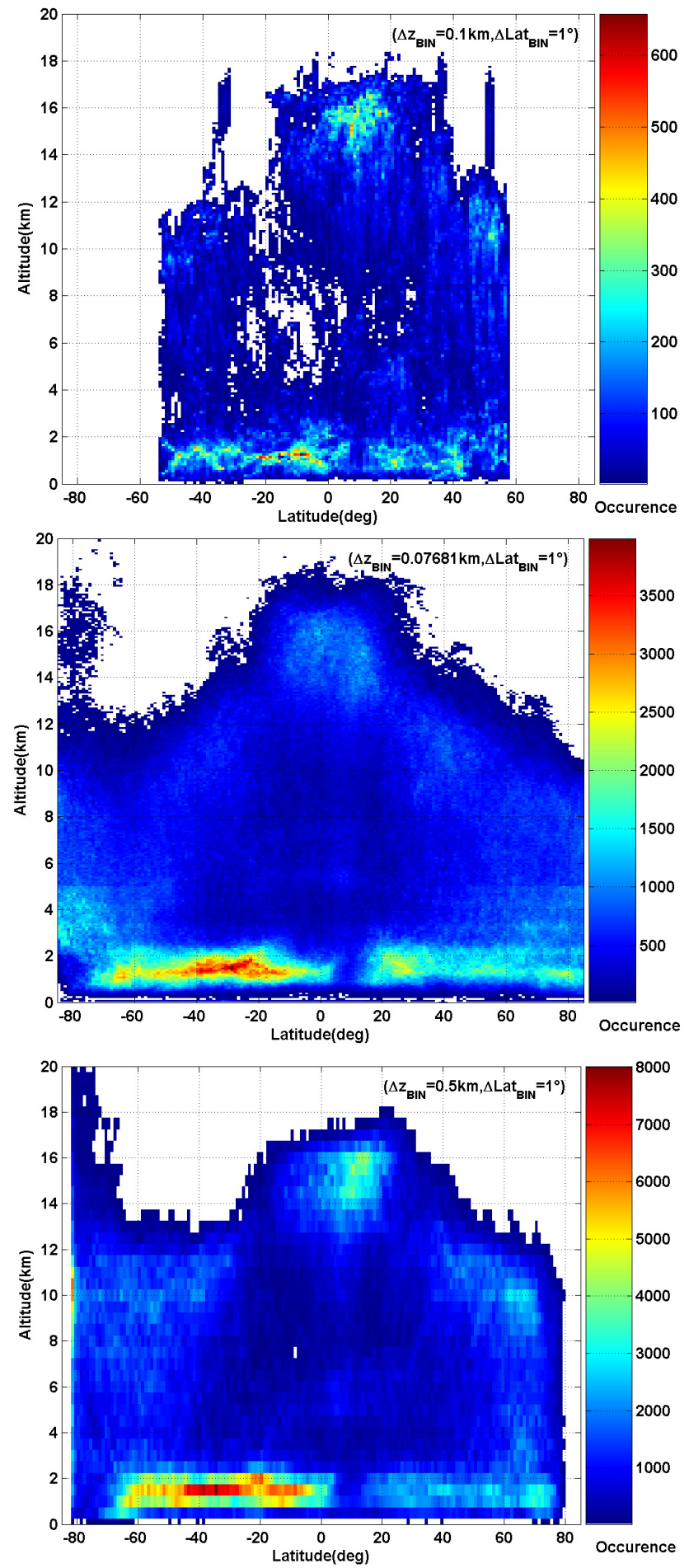

Fig. 7. Two-dimensional occurrences (latitude versus altitude) of the cloud top height from LITE (10 to 19 September 1994), GLAS (last week of September and the two first week of October 2003) and CALIOP (September 2006) measurements. 
Table 1. Separation of lidar-based cloud rerievals into low, middle, and high cloud classes for LITE (Local Method, 10-19 September, 1994), GLAS (Operational Algorithm, last week of September and two first week of October 2003) and CALIOP (Operational Algorithm, September-October 2006) measurements as determined from the ISCCP classification against low, middle and high clouds. The bottom group gives the cloud cover ratio. The first column gives the global cloud statistics, and the other columns the statistics on the three latitude intervals $\left[-60^{\circ} ;-20^{\circ}\right],\left[-20^{\circ} ; 30^{\circ}\right]$ and $\left[30^{\circ} ; 60^{\circ}\right]$.

\begin{tabular}{llllll}
\hline \multirow{3}{*}{ High } & & All latitude & {$\left[-60^{\circ} ;-20^{\circ}\right]$} & {$\left[-20^{\circ} ;+30^{\circ}\right]$} & {$\left[+30^{\circ} ;+60^{\circ}\right]$} \\
\hline \multirow{3}{*}{ Middle } & LITE & $52.4 \%$ & $37.6 \%$ & $57.4 \%$ & $56.1 \%$ \\
& GLAS & $46.5 \%$ & $47.5 \%$ & $48.3 \%$ & $42.0 \%$ \\
& CALIOP & $45.0 \%$ & $33.9 \%$ & $53.3 \%$ & $48.6 \%$ \\
& LITE & $9.0 \%$ & $10.2 \%$ & $6.6 \%$ & $12.4 \%$ \\
& GLAS & $18.8 \%$ & $19.3 \%$ & $18.3 \%$ & $19.2 \%$ \\
& CALIOP & $13.9 \%$ & $14.9 \%$ & $10.9 \%$ & $17.7 \%$ \\
& LITE & $38.6 \%$ & $52.2 \%$ & $36.0 \%$ & $31.5 \%$ \\
& GLAS & $34.7 \%$ & $33.2 \%$ & $33.4 \%$ & $38.8 \%$ \\
\hline \multirow{2}{*}{ Cover Ratio } & CALIOP & $41.1 \%$ & $51.2 \%$ & $35.8 \%$ & $33.7 \%$ \\
& LITE & $69.8 \%$ & $72.8 \%$ & $72.5 \%$ & $64.0 \%$ \\
& GLAS & $69.2 \%$ & $76.5 \%$ & $62.4 \%$ & $70.5 \%$ \\
& CALIOP & $70.5 \%$ & $78.6 \%$ & $67.5 \%$ & $64.52 \%$ \\
\hline
\end{tabular}

\section{Cross-comparison between lidar and passive space- borne instruments}

In operational cloud retrievals from passive radiometric measurements, the assumption is made that only one cloud layer is present in a satellite pixel (i.e. Platnick et al., 2003; Stubenrauch et al., 2006b). In the case of multilayered cloud structures, this assumption will introduce biases in the determination of $\mathrm{CTH}$, especially for the case of cirrus overlying a lower-level water cloud. Fortunately, spaceborne lidar can provide insight to the vertical distribution of clouds. Moreover, the determination of the $\mathrm{CTH}$ is a direct measurement, and the multilayer cloud distribution can be assessed as long as the lidar signal does not attenuate in the uppermost cloud structure.

We now compare the $\mathrm{CTH}$ distributions given by passive and active instruments. The coherence between the approaches to retrieve the CTH from spaceborne lidar measurements has been demonstrated. With the increased vertical resolution of the LITE lidar and its better signal to noise ratio, these data have been retained for the comparisons with passive instruments.

From use of the surface echo for LITE measurements, we have separated the contribution of high semi-transparent clouds from that of optically thick clouds. The result is presented in Table 2 for the latitude intervals that have been discussed earlier. We note that the occurrence of semitransparent clouds approaches $70 \%$ for all latitude bands.

\subsection{Comparison to ISCCP database}

A first comparison between the CTH CPDF between ISCCP and LITE is given in Fig. 4b. Only the ISCCP measurements within the footprint of the LITE orbit have been considered.
As specified before, only the highest cloud structure has been considered. For clouds at altitudes of less than $3 \mathrm{~km}$ (i.e., low level clouds), the ISCCP and the LITE CPDF are very similar. The ISCCP CPDF shows a cumulative probability of about $47 \%$ of cloud detected at up to $3 \mathrm{~km}$ height, which is in agreement with of the surface observation analysis by Warren et al. (1985). For clouds over $3 \mathrm{~km}$ height, significant differences occur in the number of detected CTH. The LITE $\mathrm{CTH}$ tends to place clouds at higher altitudes than ISCCP. The CPDF retrieved from LITE profiles reaches $95 \%$ at an altitude close to $16 \mathrm{~km}$ whereas that from ISCCP reaches the same value at an altitude close to $11 \mathrm{~km}$. It seems that detection of optically thin high cloud layers is problematic for IS$\mathrm{CCP}$. This leads to notable differences when comparing mean CTH retrieved from ISCCP and LITE datasets. The mean altitude of the cloud layers is much lower for ISCCP, more than $30 \%$ on average, as shown on Figs. 6 and 7. The difference is less marked in the southern hemisphere but is about $2 \mathrm{~km}$ under $20^{\circ} \mathrm{S}$ and increases toward the northern latitudes.

A different way of comparing LITE and ISCCP CTH is given in Fig. 8, which divides the CTH into the cloud classes defined by ISCCP: high (H), middle (M) and low (L) clouds. For the LITE CTH, each class is sub-divided considering the potential overlap from the other cloud layers. Our goal is to use data from active instruments to highlight the occurrence of cloud overlap.

The largest difference between LITE and ISCCP statistics $(14 \%)$ is observed in the occurrence of the high clouds. Such a difference may result from two causes. First, ISCCP may not detect all the high semi-transparent clouds. In particular, situations with optically thin cirrus clouds may be classified by ISCCP as being clear sky. This could explain in part the difference in the clear sky occurrence between the two types of measurements (12\%). Also, note that ISCCP assumes that 
Table 2. Proportion of optically thin clouds compared to the total cover of high clouds for LITE, MODIS (Chang and Li, 2005) and TOVS PATH-B (Stubenrauch et al., 2006b).

\begin{tabular}{lllll}
\hline Instrument & All latitudes & {$[-60-20]$} & {$[-20+30]$} & {$[+30+60]$} \\
\hline LITE & $70.6 \%$ & $71.3 \%$ & $72.4 \%$ & $69.4 \%$ \\
ISCCP & $87.2 \%$ & $84.62 \%$ & $87.6 \%$ & $86.0 \%$ \\
MODIS & $73.8 \%$ & $72.2 \%$ & $64 \%$ & $80.5 \%$ \\
VS PATH-B & $91.9 \%$ & $90 \%$ & $94.7 \%$ & $89.1 \%$ \\
\hline
\end{tabular}

if a cloud is present, there is a single cloud structure in the atmospheric column. The inference of CTH for optically thin cirrus is problematic and such a cloud may be assessed as being a lower-level cloud. The assumption of a single cloud structure in a satellite imager pixel can lead to biases in CTH when multilayered cloud structures exist. It is interesting to note that the multilayered cloud classes $(\mathrm{H}+\mathrm{M}),(\mathrm{H}+\mathrm{L}+\mathrm{M})$ and $(\mathrm{H}+\mathrm{L})$ retrieved from LITE profiles are redistributed in the middle and low cloud classes of the ISCCP climatology. This could explain the great percentage of middle and low cloud structures in the ISCCP products. Moreover, Evan et al. (2007) demonstrated that the long term global trends in the cloudiness from the ISCCP record are influenced by artifacts associated with satellite viewing geometry. This study underlines a non-physical decrease of the total cloud amount as given by ISCCP of about 6\% between 1987 and 2000. This can also explain partially the differences observed in the proportion of clear sky observations.

The lack of optically thin cirrus clouds in the ISCCP products is also described in Jin et al. (1996). They assessed the latitudinal spread of the thin cirrus cloud fraction, in a comparison of the ISCCP and HIRS (High Resolution Infrared Radiation Sounder) high cloud products. In all the cases and considering all the latitude range, ISCCP seems to underestimate the fraction of cirrus cloud type. In particular, we note a larger difference in the ITCZ region.

5.2 Comparison to cloud statistic from MODIS measurements

Cloud products are available from the MODerate-resolution Imaging Spectrometer (MODIS; Platnick et al., 2003) and provide global CTH. The approach assumes only a singlelayer cloud in the entire atmospheric column, and effort is underway to include multispectral approaches for the detection of multilayered clouds, specifically for the case of cirrus overlying a lower-level water cloud.

High-level and mid-level clouds are analyzed with the $\mathrm{CO}_{2}$-slicing method developed by Menzel et al. (2002); this approach infers cloud top pressure and effective cloud amount (emittance multiplied by cloud fraction) for clouds at pressures lower than approximately $700 \mathrm{hPa}$. The MODIS results are similar to those presented in this study for the
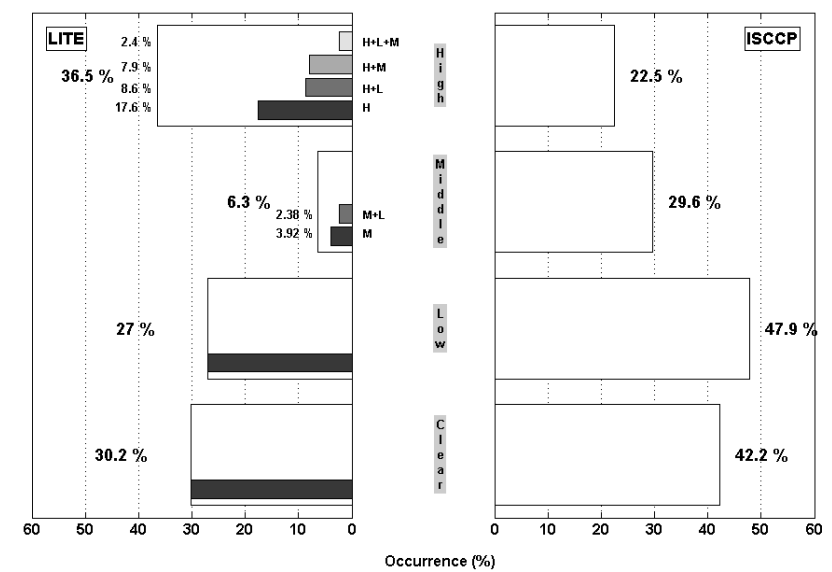

Fig. 8. Distribution of each cloud class determined from LITE measurements following the classification of ISCCP in term of high $(\mathrm{H})$, middle (M) and low (L) clouds (left figure). For each class the percentage corresponding to the multilayered clouds by the other cloud classes is given. The bottom percentage gives the occurrence of the clear sky. The ISCCP-DX classification is given on the right figure.

spaceborne lidar systems. In particular, the ratio of semitransparent clouds to the total cover of high clouds shown in Table 2 is closer to the results deduced from LITE dataset.

\subsection{Comparison to clouds statistics from TOVS and others}

Other cloud products derived from passive sensors, such as TOVS Path-B (Stubenrauch et al., 2006a, b), or from AIRS (Atmospheric Infrared Sounder), identify more cirrus clouds than ISCCP. From analysis of TOVS Path-B products from 1987 to 1995 , the percentage was $\sim 4 \%$ in the middle latitudes $\left(30^{\circ}-60^{\circ} \mathrm{N}\right.$ and $\left.30^{\circ}-60^{\circ} \mathrm{S}\right)$, and up to $20 \%$ in the Tropics $\left(15^{\circ} \mathrm{N}-15^{\circ} \mathrm{S}\right)$. For the AIRS L2 data analyses, the ITCZ high cloud amount is retrieved as being $10 \%$ larger than that from ISCCP (Stubenrauch et al., 2006a). As for MODIS, the ratio of semi-transparent clouds to the total cover of high clouds shown in Table 2 indicates that a higher proportion of optically thick clouds than that derived from LITE measurements for all the latitudes. 


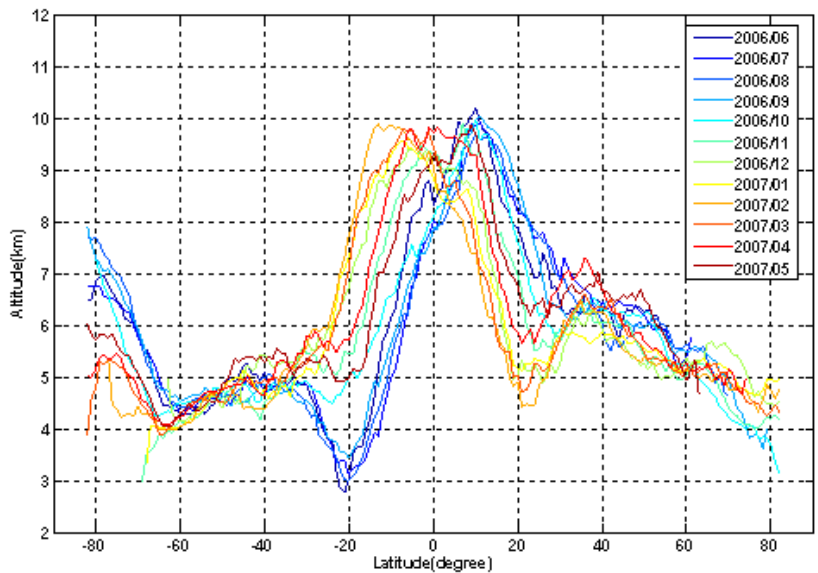

Fig. 9. Monthly average of the mean cloud top height against the latitude. Only the highest cloud structure retrieved from the operational algorithm applied on CALIOP measurements has been used between June 2006 and May 2007.

\subsection{Impact of the seasonal variation on the CALIOP de-} rived parameters

We find a very strong difference in the mean $\mathrm{CTH}$ as a function of latitude between the passive and active measurements, particularly for the tropical areas (see Fig. 6). This region plays an important role in the hydrological and radiation energy balance (Forster et al., 2007) and the differences observed can influence our understanding of potential feedback mechanisms. Earlier, we associated the maximum of the CTH with the position of the ITCZ for September. From the annual observations of CALIOP, we are able to further study this aspect and to analyze the interannual variability of the CTH. Figure 9 shows the temporal evolution of the CTH distribution from June 2006 to May 2007.

The mean values of CTH are comparable for both the middle and the northern polar latitudes. Large differences appear for both the tropical and the southern polar latitudes. We discuss hereafter the causes of these differences that can have a considerable impact on the cloud climatology.

\subsection{Tropical variability of the mean $\mathrm{CTH}$}

As shown in Fig. 9, the maximum of the $\mathrm{CTH}$ distribution moves from north to south of the equator with the ITCZ between February and August. Figure 10 shows the location of the ITCZ retrieved by Waliser et al. (1993) with the CTH distribution. We note that the correspondence between the ITCZ location and the mean CTH retrieved from CALIOP is very similar. This confirms that the maximum of the median value of the $\mathrm{CTH}$ can be associated with the mean position of the ITCZ. The extreme positions of ITCZ are $12^{\circ} \mathrm{N}$ during boreal summer (August 2006) and $7^{\circ} \mathrm{S}$ during boreal winter (February 2007).

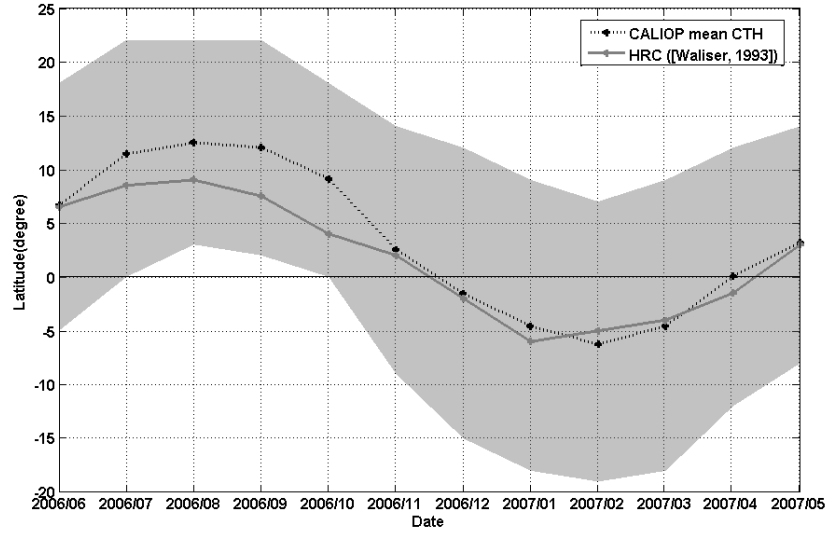

Fig. 10. Seasonal variation of the mean CTH retrieved from CALIOP measurements performed between June 2006 and May 2007 against the latitude (dotted line). The grey area gives the peak width of tropical CTH distribution (Fig. 9) taken arbitrary at $8 \mathrm{~km}$ height. The black full line gives the annual cycle of the ITCZ computed from 17 years of HRC (Hightly Reflective Cloud) data (January 1971 to December 1987) by Waliser et al. (1993).

The ITCZ tends to reside longer in the Northern hemisphere than in the Southern hemisphere (7 months and 5 months, respectively). The width of the tropical CTH distribution at an arbitrary height of $8 \mathrm{~km}$ is shown as the grey area in the Fig. 10. This belt seem to be largest between November and March (close to $7^{\circ} \mathrm{S}$ ), and minimal between July and October (close to $12^{\circ} \mathrm{N}$ ).

This asymmetry, which could seem in contradiction with the symmetry of the solar radiation to the equator, has been well documented, and modeled by numerous authors such as Philander et al. (1996), Li (1997) and Hu et al. (2007). The fundamental cause of the asymmetry in the eastern Pacific is the tilt of the western coast of the Americas, which perturbs the sea surface temperature in the vicinity of the coastal region through a coastal wind-upwelling mechanism. The asymmetry in the Atlantic results from the land-ocean thermal contrast between the bulge of northwestern Africa and the ocean to the south. The ocean-atmosphere interactions act as an amplifier to enhance the asymmetry that is set up by the continental or coastal morphology (Li, 1997).

\subsection{Influence of polar stratospheric clouds}

In a previous Sect. 4.2.1, we highlighted the potential impact of the PSC on the CTH statistics for the southern polar latitudes. PSC are both high altitude and optically thin clouds but they can be detected from lidar measurements (see Fig. 7 under $60^{\circ} \mathrm{S}$ ). They play a major role in stratospheric chemistry and in particular on ozone depletion (i.e. Solomon, 1999).

Figure 9 shows also the mean CTH of all the clouds retrieved for southern polar latitudes (between $70^{\circ} \mathrm{S}$ and $90^{\circ} \mathrm{S}$ ). The mean $\mathrm{CTH}$ significantly evolves during the year 
with the higher values between June and October $(\sim 7 \mathrm{~km}$ at $80^{\circ} \mathrm{S}$ ) and smaller values between February and April $(\sim 5 \mathrm{~km})$ at $80^{\circ} \mathrm{S}$. July is an intermediate situation with a mean CTH close to $6 \mathrm{~km}$. In December and January the detection of cloud structures is not efficient due to the duration of the day. The signal to noise ratio in lidar measurements for optically thin clouds is lower due to the influence of sky radiance at $532 \mathrm{~nm}$.

There are very few instruments able to detect PSC and very few existing studies about the climatology of this type of optically thin cloud. In a previous study, David et al. (1998) showed a percentage of about $70 \%$ of detected PSCs between 11 and $26 \mathrm{~km}$ height. Höpfner et al. (2007) used MIPAS instrument analyses to investigate the inter-annual occurrence of PSC. They show that PSC mainly occur from May to the end of October when the stratospheric temperature is very cold, with a maximal occurrence retrieved between mid-July to the end of August.

Hence, the increase of the mean CTH observed between GLAS and CALIOP measurement periods (Fig. 6) is likely due to a more important presence of PSC during year 2006 than during year 2003.

\section{Summary and conclusions}

To investigate the statistical distribution of the cloud top heights $(\mathrm{CTH})$, we use the observations from three spaceborne lidar missions: LITE, GLAS and CALIPSO. We developed a methodology to infer the CTH from the lidar measurements. This methodology was compared with the operational algorithms of GLAS and CALIOP missions and proved to be quite powerful. One way of comparing the CTH from these lidars is through the cloud probability density functions (CPDF). Optically thin cirrus clouds are better identified from LITE profiles because these measurements have a higher signal to noise ratio (SNR) than with the other lidars. The better SNR is mainly due to the altitude of the shuttle $(\sim 240 \mathrm{~km})$ compared to the GLAS and CALIOP satellites ( $\sim 590$ and $\sim 705 \mathrm{~km}$, respectively).

Important variations are noted from a comparison of the CTH statistics from LITE and those from ISCCP, although these comparisons cover a very short time period. These differences are noted especially for the high clouds but also on the mean CTH. Low clouds are well identified by the two types of instrument (i.e. active and passive remote sensing sensors). We note that a similar comparison using MODIS cloud products based on the $\mathrm{CO}_{2}$ slicing method led to results more similar to those deduced from the lidar measurements.

Natural causes of variability can be related in the tropical areas to the position of the ITCZ and in the southern polar regions with the monthly and inter-annual cycles of the PSC. In particular, important differences can be recorded from one year to another as between September 2003 and September 2006 when the mean CTH increases from 6 to
$9 \mathrm{~km}$, respectively. The first year of measurements was obtained from GLAS and the second by CALIOP. The observed differences are not thought to be caused by differences in the instruments but from changes in the atmosphere itself.

Such a study has highlighted that the use of space-borne lidar observations performed at the global scale is a potentially powerful way of assessing critical parameters of the cloud distribution that may significantly change under the influence of human activities.

Acknowledgements. The authors would like to thank AlcatelSpace, now Thalès-Alenia Space and CNES, for the granting of one of them (S. Berthier). This study was supported by CEA, and CNRS. The authors note their deep respect for their esteemed colleague Pierre Couvert, now deceased, who took part in this work.

Edited by: Q. Fu

\section{References}

Abshire, J. B., Sun, X., Riris, H., Sirota, J. M., McGarry, J. F., Palm, S., Yi, D., and Liiva, P.: Geoscience Laser Altimeter System (GLAS) on the ICESat Mission: On-orbit measurement performance, Geophys. Res. Lett., 32, L21S02, doi:10.1029/2005GL024028, 2005.

Baum, B. A., Uttal, T., Poellot, M., Ackerman, T. P., Alvarez, J. M., Intrieri, J., Starr, D. O'C., Titlow, J., Tovinkere, V., and Clothiaux, E.: Satellite remote sensing of multiple cloud layers. J. Atmos. Sci., 52(23), 4210-4230, 1995.

Baum, B. A., Frey, R. A., Mace, G. G., Harkey, M. K., and Yang, P.: Nighttime multilayered cloud detection using MODIS and ARM data., J. Appl. Meteor., 42, 905-919, 2003.

Burkert, P., Fergg, F. and Fischer, H.: A compact high resolution Michelson interferometer for passive atmospheric sounding (MIPAS), IEEE Trans. Geosci. Remote Sensing GE-21,345, 1983.

Chang, F. L. and Li., Z.: A new method for detection of cirrus overlapping water clouds and determination of their optical properties, J.Atmos. Sci., 62, 3993-4009, 2005.

Chazette P., Pelon, J., and Mégie, G.: Determination by spaceborne backscatter lidar of the structural parameters of atmospheric scattering layer, App. Opt., 40, 3428-3440, 2001.

David, C., Bekki, S., Godin, S., Megie, G., and Chipperfield, M. P.: Polar stratospheric clouds climatology over Dumont d'Urville between 1989 and 1993 and the influence of volcanic aerosols on their formation, J. Geophys. Res., 103, 22 163-22 180, 1998.

Evan, A. T., Heidinger, A. K., and Vimont, D. J: Arguments against a physical long-term trend in global ISCCP cloud amounts, Geo. Res. Lett., 34, L04701, doi:10.1029/2006GL028083, 2007.

Flatau, P. J., Cotton, W. R., Stephens, G. L., Dalu, G. A., and Heymsfield, A. J.: Mixed layer model of cirrus clouds - Growth and dissipation mechanisms, Symposium on the Role of Clouds in Atmospheric Chemistry and Global Climate, Anaheim, CA; United-States; 30 January-3 February 1989, 151-156, 1989.

Forster, P., Ramaswamy, V., Artaxo, P., Berntsen, T., Betts, R., Fahey, D. W., Haywood, J., Lean, J., Lowe, D. C., Myhre, G., Nganga, J., Prinn, R., Raga, G., Schulz, M., and Van Dorland, R.: Changes in Atmospheric Constituents and in Radiative Forcing, in: Climate Change 2007: The Physical Science Basis. Con- 
tribution of Working Group I to the Fourth Assessment Report of the Intergovernmental Panel on Climate Change, edited by: Solomon, S., Qin, D., Manning, M., Chen, Z., Marquis, M., Averyt, K. B., Tignor, M., and Miller H. L., Cambridge University Press, Cambridge, United Kingdom and New York, NY, USA, 2007.

Grant, W. B., Browel, E. B., Butler, C. F., and Nowicki, G. D.: LITE measurements of biomass burning aerosols and comparisons with correlative airborne lidar measurements of multiple scattering in the planetary boundary layer, Advances in Atmospheric Remote Sensing with Lidar, edited by: Ansmann, A., Neuber, R., Rairoux, P., Wandinger, U., Springer-Verlag, Berlin, 153-156, 1997.

Heidinger, A. K. and Pavolonis, M. J.: Global daytime distribution of overlapping cirrus cloud from NOAA's Advanced Very High Resolution Radiometer, J. Climate, 18, 4772-4784, 2005.

Höpfner, M., Grabowski, U., Stiller, G. P., Von Clarmann, T.: Climatology of Artic and Antarctic polar stratospheric clouds (PSCs) from 2002-2007 as observed by MIPAS, POSTER EGU2007-A-08879 AS3.13-1FR1P-0120, 2007.

$\mathrm{Hu}$, Y., Li, D., and Liu, J.: Abrupt seasonal variation of the ITCZ and the Hadley circulation, Geophys. Res. Lett., 34, L18814, doi:10.1029/2007GL030950, 2007.

Hugues, N. A. and Henderson-Sellers, A.: Global 3-Dnephanalysis of total cloud amount: Climatology for 1979, J. Clim. and Appl. Meteor., 24, 669-686, doi: 10.1175/15200450(1985)024<0669:GNOTCA > 2.0.CO;2, 1985.

Ingmann, P., Straume-Lindner, A. G., and Werh T.: ESA spaceborne lidars in preparation or planned, in: Proceedings, 24th ILRC, edited by: Hardesty, M. and Mayor, S., NCAR, Boulder, CO, 2008, 1109-1110, 2008.

Jin, Y. and Rossow, W. B.: Detection of cirrus overlapping low-level clouds, J. Geophys. Res., 102, 1727-1737, 1997.

Kent, G. S., Winker, D. M., Osborn, M. T., and Skeens, K. M.: A model for the separation of cloud and aerosol in SAGE II occultation data, J. Geophys. Res., 98(D11), 20725-20735, doi:10.1029/93JD00340, 1993.

Li, T.: Air-sea interactions of relevance to the ITCZ: Analysis of coupled instabilities and experiments in the hybrid coupled GCM, J. Atmos. Sci., 54, 134-147, 1997.

Liu, Z., Vaughan, M. A., Winker, D. M., Hostetler, C. A., Poole, L. R., Hlavka, D., Hart, W., and McGill, M.: Use of probability distribution functions for discriminating between cloud and aerosol in lidar backscatter data, J. Geophys. Res., 109, D15202, doi:10.1029/2004JD004732, 2004.

Menzel, W. P., Baum, B. A., Strabala, K. I. and Frey, R. A.: Cloud top properties and cloud phase-Algorithm Theorical Basis Document: ATBD-MOD-04, p. 61. Available at http://modis-atmos. gsfc.nasa.gov/ , 2002.

Nasiri, S. L. and Baum, B. A.: Daytime multilayered cloud detection using multispectral imager data, J. Atmos. Ocean. Technol., 21, 1145-1155, 2004.

Palm, S. P. and Spinhirne, J.: The detection of clouds, aerosol and marine atmospheric boundary layer characteristics from simulated GLAS data. The 19th International Laser Radar Conference, Annapolis, Md, 6-10 July, 1998.

Palm, S. P., Hart, W., Hlavka, D., et al.: GLAS atmospheric data products, Algorithm Theor. Basis. Doc. ATBD-GLAS-01, version 4.2, Earth Obs. Syst. Proj. Off., Greenbelt, Md. avail- able at http://www.csr.utexas.edu/glas/pdf/glasatmos.atbdv4.2. pdf, 2002.

Pavolonis, M. J. and Heidinger, A. K.: Daytime cloud overlap detection from AVHRR and VIIRS, J. Appl. Meteorol. 43, 762778, 2004.

Philander, S. G. H., Gu, D., Halpern, D., Lambert, G., Lau, N.-C., Li, T., and Pacanowski, R. C.: Why the ITCZ is mostly north of the equator, J. Climate, 9, 2958-2972, 1996.

Pitts, C., Thomason, L. W., Poole, L. R., and Winker, D. M.: Characterization of Polar Stratospheric Clouds with SpaceBorne Lidar: CALIPSO and the 2006 Antarctic Season, Atmos. Chem. Phys. Discuss., 7, 7933-7985, available at www. atmos-chem-phys-discuss.net/7/7933/2007/, 2007.

Platnick, S., King, M. D., Ackerman, S. A., Menzel, W. P., Baum, B. A., Riedi, J. C.; and Frey, R. A.: The MODIS cloud products: Algorithms and example from Terra, IEEE Trans. Geosci., 41, 459-473, 2003.

Platt, C. M. R., Young, S. A., Manson, P. J., Patterson, G. R., Marsden, S. C., Austin, R. T., and Churnside, J. H.: The optical properties of equatorial cirrus from observations in the ARM Pilot Radiation Observation Experiment, J. Atmos. Sci, 55, 1977-1996, doi: 10.1175/1520-0469(1998)055<1977:TOPOEC>2.0.CO;2, 1998.

Rossow, W. B., Mosher, F., Kinsella, E., Arking, A., Desbois, M., Harrison, E., Minnis, P., Ruprecht, E., Seze, G., Simmer, C., and Smith, E.: ISCCP cloud algorithm intercomparison, J. Climate Appl. Meteor., 24, 877-903, doi:10.1175/15200450(1985)024<0887:ICAI>2.0.CO;2, 1985.

Rossow, W. B. and Schiffer, E. A.: ISCCP Cloud Data Products, Bull. Amer. Meteor. Soc., 72, 2-20, doi:10.1175/15200477(1991)072<0002:ICDP>2.0.CO;2, 1991.

Schiffer, R. A. and Rossow, W. B.: The International Satellite Cloud Climatology Project (ISCCP): The first project of the World Climate Research Program, Bull. Am. Meteorol. Soc., 64, 779-784, 1983.

Solomon, S.: Stratospheric ozone depletion: A review of concepts and history, Rev. Geophys., 37, 275-316, 1999.

Stephens, G. L.: Cloud feedbacks in the climate system: A critical Review, J. Clim., 18, 237-273., doi:10.1175/JCLI-3243.1, 2005.

Stowe, L. L.: Evaluation of NIMBUS 7 THIR/CLE and air force three-dimensional nephanalysis estimates of cloud amount, J. Geophys. Res., 89, 5370-5380, 1984.

Stubenrauch, C. J., Armante, R., Abdelaziz, G., Crevoisier, C., Pierangelo, C., Scott, N. A., and Chedin, A.: Cloud properties from AIRS, 15th International TOVS Study Conference Proceeding, Matera, Italy, 4-10 October 2006, 2006a.

Stubenrauch, C. J., Chédin, A., Rädel, G., Scott, N. A., and Serrar, S.: Cloud Properties and Their Seasonal and Diurnal Variability from TOVS Path-B, 2007, J. Climate, 19(21), 5531-5553, doi:10.1175/JCLI3929.1, 2006b.

Susskind, J., Reuter, D., and Chahine, M. T.: Cloud fields retrieved from HIRS2/MSU sounding data, J. Geophys. Res., 92D, 40354050, 1987.

Thome, K., Reagan, J., Geis, J., Bolt, M., and Spinhirne, J.: Validation of GLAS calibration using ground- and satellite-based data, Geoscience and Remote Sensing Symposium, 2004. IGARSS '04. Proceedings, 2004 IEEE International, 4, 2468-2471, 2024 September 2004, available at http://ieeexplore.ieee.org/iel5/ 9436/29947/01369793.pdf, 2004. 
Vaughan, M. A., Young, S. A., Winker, D. M., Powell, K. A., Omar, A. H., Liu, Z., Hu, Y., and Hostetler, C. A.: Fully automated analysis of space-based lidar data : An overview of the CALIPSO retrieval algorithms and data products, Proc. Spie., 5575, 16-30, doi:10.1117/12.572024, 2004.

Waliser, D. E. and Gautier, C.: A satellite-derived climatology of the ITCZ, J. Climate, 6, 2162-2174, doi:10.1175/15200442(1993)006<2162:ASDCOT>2.0.CO;2, 1993.

Warren, S. G., Hahn, C. J., and London, J.: Simultaneous occurrence of different cloud types, J. Clim. Appl. Meteorol., 24, 658-667, doi:10.1175/15200450(1985)024<0658:SOODCT > 2.0.CO;2, 1985.

Winker, D. M., Couch, R. H., and McCormick, M. P.: An overview of LITE: NASA's Lidar In Space Technology Experiment, Proc. IEEE, 84, 164-180, 1996.

Winker, D. M.: Cloud Distribution Statistics from LITE, in: 19th International Laser Radar Conference, edited by: Singh, U. N., Ismail, S., and Schwemmer, G. K., 955-958, Annapolis, Maryland, 1998.
Winker, D. M., Pelon, J., and McCormick, M. P: The CALIPSO mission: Aerosols and cloud observation from space, Proc. ILRC 21, edited by: Bissonnette, L., Roy, G., and Vallee, G., 735-738, 2002.

Winker, D. M. and Hunt, B.: First Results from CALIOP, Proc. Third Symposium on LIDAR Atmospheric Applications, 87th AMS Annual Meeting, San Antonio, Texas, 15-18 January 2007, 2007.

Wylie, D. P., Jackson, D. L., Menzel, W. P., and Bates, J. J.: Trends in global cloud cover in two decades of HIRS observations, J. Climate, 18, 3021-3031, 2005.

Yeh, H. Y. and Liou, K. N.: Remote sounding of cloud parameters from a combination of infrared and microwave channels: A parameterization approach, J. Appl. Meteor., 22, 201-213, doi:10.1175/1520-0450(1983)022<0201:RSOCPF > 2.0.CO;2, 1983. 